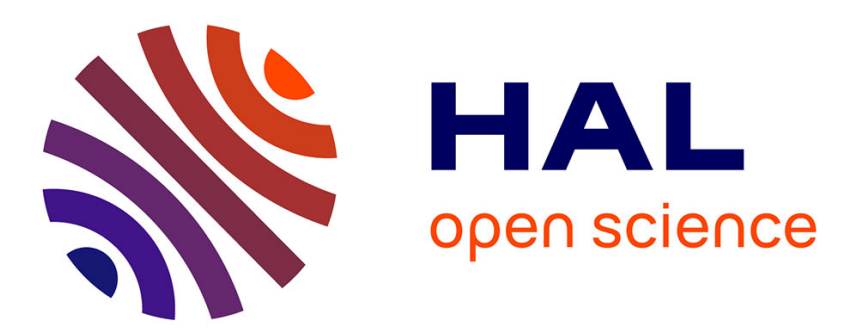

\title{
THE FRAGMENTATION STATISTICS OF DUCTILE METALS AND THEIR SHEAR BANDS EVOLUTION
}

E. Hirsch

\section{To cite this version:}

E. Hirsch. THE FRAGMENTATION STATISTICS OF DUCTILE METALS AND THEIR SHEAR BANDS EVOLUTION. Journal de Physique IV Proceedings, 1991, 01 (C3), pp.C3-781-C3-784. 10.1051/jp4:19913110 . jpa-00249913

\section{HAL Id: jpa-00249913 https://hal.science/jpa-00249913}

Submitted on 1 Jan 1991

HAL is a multi-disciplinary open access archive for the deposit and dissemination of scientific research documents, whether they are published or not. The documents may come from teaching and research institutions in France or abroad, or from public or private research centers.
L'archive ouverte pluridisciplinaire HAL, est destinée au dépôt et à la diffusion de documents scientifiques de niveau recherche, publiés ou non, émanant des établissements d'enseignement et de recherche français ou étrangers, des laboratoires publics ou privés. 


\title{
THE FRAGMENTATION STATISTICS OF DUCTILE METALS AND THEIR SHEAR BANDS EVOLUTION
}

\author{
E. HIRSCH
}

Israel Military Industries, P.O. Box, 1044 Ramat Hasharon, 47100, Israel

\begin{abstract}
Résumé - On monte comment le frottement latéral de bandes de cisaillement contigües est à l'oxigine du mécanisme qui contrôle l'évolution de la déformation plastique, en état de traction. La vitesse de propagation $\mathrm{V}_{\mathrm{p} 2}$ est le paramètre qui gouverne la fragmentation ductile; la localisation qui conduit à cette fragmentation se révèle comme résultant des variations statistiques de la contrainte d'écoulement associées au mécanisme de frottement.

Abstract - The friction between the sides of shear bands is show to be the source of the mechanism by which plastic deformation propagates under tensile force. The velocity of propagation, $V$, is the material parameter which controls ductile fragmentation. The localization loading to this fragmentation is shown to result from the statistical variations of the yield strength associated with this friction mechanism.
\end{abstract}

\section{1.- Introduction}

It was shown in a recent publication(1) that the fragmentation process of ductile metals has four stages: - stable flow, - early localization due to instability, - final localization obeying POISSON STATISTICS, and - break-up along shear bands continuing to slide until their sides separate. The Poisson statistics, found in the analysis of shaped charge jet segments data, indicates that the final localization stage occurs when three out of four shear bands slow down to final rest while the fourth forms the two edges of neighbouring segments. This yields the distribution:

$$
\operatorname{Pr}(I)=\left(3^{I} / I !\right) \cdot e^{-3}
$$

where I is the number of stopping shear bands in a segment, the length of which is equal to:

$$
L(I)=\left(I_{\text {average }} / 4\right) \cdot(I+I)
$$

This fragmentation statistics was also extended to describing the two dimensional break-up of expanding spherical shells $(2,3)$ yielding a very consistant picture: - The material parameter which controls ductile fragmentation is the average velocity between neighbouring fragments, $V$, which was first suggested at Ref. 4 for calculating the shaped charge jet brbakk-up time.

It is shown here that this velocity, which is equal to the component in the direction of elongation of the maximum slide velocity occurring in the material, results from the friction between the sides of the sliding shear bands. Friction 
in sliding shear bands is the mechanism of propagating plastic deformation in tension and $V_{p l}$ is the propagation (information) velocity of this mechanism.

\section{2.- Plastic Deformation Transfer Along a Stretching Specimen}

A coin at rest is put on the surface of a table which moves horizontally with the velocity $\Delta^{V}$. How long will it take the friction between the table surface and the coin to make the coin move together with the table surface if the friction force per unit area between the coin and the table is equal to $\Delta \sigma_{s}$, the coin mass density is $\rho$ and the coin thickness is equal to $\Delta^{\bar{X}}$. By conservation of momentum we get:

$$
\rho \Delta^{\mathrm{X}} \Delta_{\mathrm{s}}^{\mathrm{V}}=\Delta \sigma_{\mathrm{s}} \Delta^{t}
$$

where $\Delta^{t}$ is the time period needed for equalizing the coin and table velocities. This equation may be interpreted in two ways. By writing:

$$
\rho \Delta^{X}\left({ }_{\Delta} V_{s} / \Delta t\right)=\Delta G_{s}
$$

We get a Newton's second law relation: Force = mass times acceleration. If however we write:

$$
0 \Delta_{s}^{V}(\Delta x / \Delta t)=\Delta G_{s}
$$

we get an expression for the velocity $\Delta \mathrm{X} / \Delta^{t}$ with which the slide motion is transfered from one layer to a neighburing one.

We identify this velocity with the maximum slide velocity possible $2^{\frac{1}{2}} v_{\text {pl }}$ as the table and coin in the above example represent the two sides of a slip pl plane which is formed at $45^{\circ}$ with respect to the direction of elongation. (At this specific angle the velocity $\Delta^{X} / \Delta t$ and the velocity $\Delta_{S}$ yield a resultant velocity vector pointing in the direction of elongation when they become equal. Thus, $\Delta V_{s}$ can't become larger than $\left.\Delta \mathrm{X} / \Delta^{t}\right)$.

Denoting the ${ }_{1}$ components in the direction of elongation of the variables in Ea. 5 $\Delta^{V}=\Delta_{\mathrm{s}} / 2^{\frac{2}{2}}$ and $\Delta G=\Delta G_{\mathrm{s}} / 2$ respectively we can write E. 5 identically to the way it is written in Ref. I where it was reached using a totally different approach:

$$
\Delta G=\rho V_{\mathrm{p} 1} \Delta^{\mathrm{V}}
$$

This equation relater the slide velocity of the slip bands, $\Delta^{V}$, with the local difference $\Delta 6$ in the average yield strength 6 through the impedance $\rho V_{p l}$. equation $\mathrm{P}=\rho \mathrm{U} \mathrm{u}$ where $\mathrm{P}$ is the shock overpressure; $U$ is the shock velocity and $u$ is the particle velocity behind the shock wave front. In both physical phenomena it is the material velocity which initiates the disturbance, which then travels with the velocity which is characteristic to specific phenomenon, the front of the disturbance being where the pressure rise is detected. However, in $\mathrm{E}_{\mathrm{q}}$. it is the friction rather than the compression by which the wave goos along the elongating material.

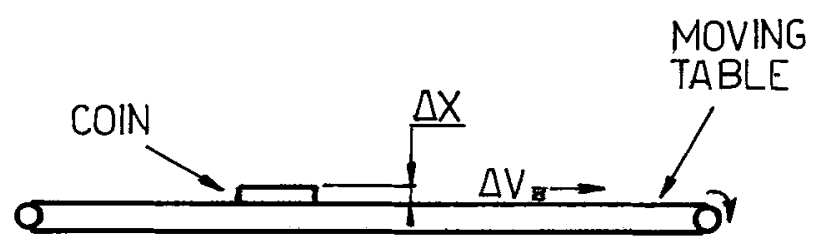

Fig 1 


\section{3.- The Localization Mechanism}

The linear relation between $\Delta^{V}$ and $\Delta G$ cannot explain the localization phenomena as is, because a smooth linear relation tends to stabilize the motion. A faster sliding slip band will increase the yield strength dynamically comparing to a slower sliding slip band and this will tend to equalize their slide velocity, to make the stress uniform throughout the elongating specimen. The localization can be explained however if we take into account the statistical variations in the yield stress which are associated with the slide motion. It is possible to look at the yield stress as a sum of two components: $\Delta 6$ which is related to $\Delta V$ by equation 6 and the "static" component, 6 , which is not proportional to $\Delta^{V}$. In reality however both components vary during the slide motion of a slip band due to the fact that the contact between the sides occurs between changing places (points) as the slide goes on. The sides (banks) of a slip plane are not smooth because the slip band outs through all kinds of microstructures of the metal, which typically are of the grain size (Ref. 5).

This constant change in the form of the contact between the slip band sides must introduce statistical variations in the yield strength which are random in nature but limitted in their range. This situation can be expressed mathematica$1 \mathrm{y}$ by assigning Gaussian distributions to the above mentioned yield strength components, as illustrated in Fig. 2.

\section{PROBABILITY DENSITY}

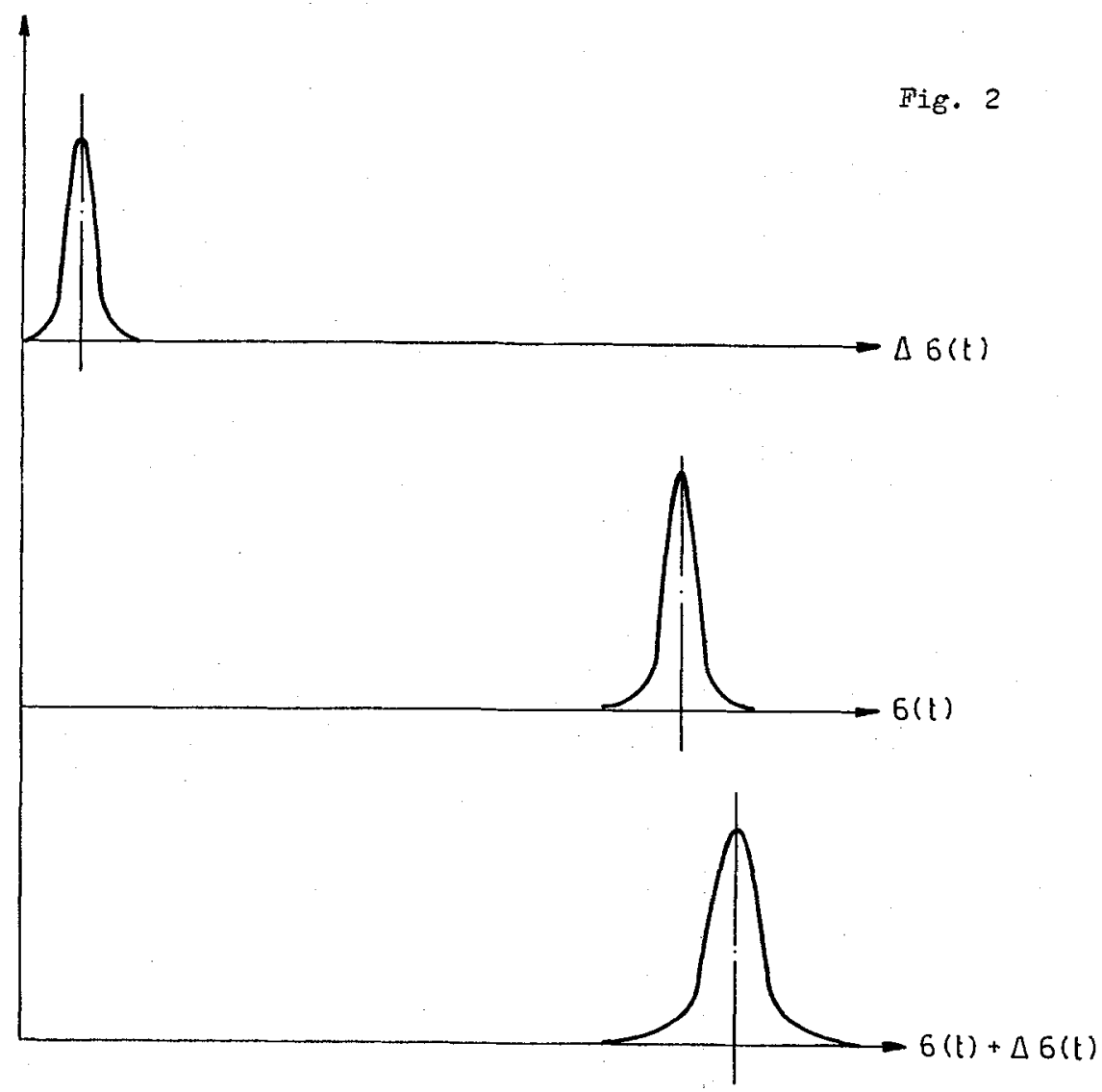


The change of 6 and $\Delta G$ within their respective Gaussian distributions is a result of many contributions, of which the change in the location of contact between the shear band sides is probably the most significant. We also have the influence of release waves arriving from neighbouring shear bands, the nature of the friction, which may vary between easy short slides and strong slowing dowr barriers and the heat softening. The heat softening destabilizes the plastic flow by making the friction at slow slide motion larger than the theoretical value of Eq. 6 due to the more effective cooling by the heat conduction when less heat is generated per time unit. This increases the likelihood of those shear bands which happen to reduce their slide velocity to remain slow or stop sliding. It also increases the likelihood of those which, statistically increase their slide velocity, to keep sliding fast. The number of sliding shear bands thus reduces with time progress, a phenomenon we call localization.

It is clear however, that the destabilizing effect of the heat softening, may not be enough to overcome the stabilization by the dynamic friction (Ba. 6) without the help of the statistics described above, up to very large elongations.

The Poisson distribution, which characterizes the fragmentation statistics, as reported at Ref. 1, follows probably, this localization meghanism as a natural end when the slide velocity approaches the limit of $2^{2} v_{p l}$.

\section{4.- Summary}

It was shown that the friction between the sides of shear bands explains the mechanics of the localization and break-up of elongating ductile metals as described at Refs. $1,2,3$ and explains the role of the $V_{p l}$ parameter as the
plastic deformation velocity.

It is also shown that the statistical variations of the yield stress, associated with the shear bands slide motion, plays a crucial role in the destabilization of the plastic flow, which leads to the localization process we observe in ductile metals which are not superplastic.

\section{5.- References}

1. E. Hirsch, "The Effect of the Liner Metalurgical State on the Shaped Charge Jet Break-up Time".Propellants, Explosives, Pyrotschnics 15, 166-176 (1990).

2. H. Hirsoh, "The Natural Mesh for Problems of Fragmenting Ductile Metal Shells" Proceedings of the Third International Conference on Hyperbolic Problems, Uppsala Sweden, June 11 - 15, 1990.

3. E. Hirsch, "The Natural Pragmentation of Thin Ductile Metal Shells". Proceedings of the 12 th International Symposium on Ballistics. Oct.30-Nov, Ist. San Antonio, Texas,1990. pp $327-336$.

4. B. Hirsch, "A Formula for the Shaped Charge Jet Break up-Time". Propellants and Explosives 4,89-94 (1979).

5. P.M.B.Slate, M.J.W.Billings, and P.J.A.Fuller, "The Rupture Behaviour of Metals at High Strain Rates". Journal of the Institute of Metals, 25, 244-251(1967) 6. A.H. Cottrell, Chartered Mech. Fng., 4, 448 (1957).

7. G.D. Fearnhough, "The Physicel Basis of Yield and Frecture" (Conference Series No. 1), p.88.(1966) London (Inst.Physios and Physical Society). 